Collaborative logistics from the perspective of freight transport companies Peer-reviewed author version

VERDONCK, Lotte (2017) Collaborative logistics from the perspective of freight transport companies. In: 4OR-A Quarterly Journal of Operations Research, 16(1), p. 107-108.

DOI: $10.1007 / \mathrm{s} 10288-017-0353-3$

Handle: http://hdl.handle.net/1942/25635 


\title{
Collaborative logistics from the perspective of freight transport companies
}

\author{
Lotte Verdonck
}

the date of receipt and acceptance should be inserted later

This is a summary of the author's PhD thesis supervised by Gerrit Janssens, An Caris and Katrien Ramaekers and defended on 22 May 2017 at the Universiteit Hasselt. The thesis is written in English and is available from the author upon request at lotte.verdonck@uhasselt.be.

The thesis studies horizontal logistics cooperation in depth on a strategic and operational level. Horizontal collaboration between logistics service providers has become an important research area, since severe competition in global markets, rising costs, a growing body of transport legislation and heightened customer expectations have caused profit margins of organisations to shrink. Engaging in a horizontal logistics cooperation provides various efficiency improving opportunities. However, collaboration projects also have significant failure rates due to their inherent complexity.

Current research on horizontal logistics collaboration mainly focuses on describing its opportunities, challenges and structure or demonstrates its cost reduction potential. However, the extent and long-term sustainability of collaborative benefits highly depend on the characteristics of the collaboration, its partners and the applied allocation mechanisms. In this context, the research contribution of the doctoral thesis is twofold. First, the benefits associated with horizontal logistics cooperation are quantified within differing collaborative environments. Second, the conditions necessary to achieve collaborative synergy are investigated. More specifically, the impact of various collaboration strategies, partner characteristics and allocation mechanisms on collaborative performance and stability is statistically analysed in three collaborative settings.

The thesis provides support to freight transport companies considering collaboration by analysing three horizontal cooperation settings: two distinct unimodal carrier coalitions and one intermodal shipper coalition. First, in the majority of horizontal carrier alliances customer orders from all participating 
companies are combined and collected in a central pool and efficient route schemes are set up for all orders simultaneously using appropriate vehicle routing techniques. This collaboration approach may be labelled joint route planning. In this way, scale economies, in terms of reduced travel distance, empty vehicle movements and number of required trucks, could be obtained by merging the distribution regions of all collaboration partners. Second, in line with the broad definition of logistics including both the movement and storage of freight, a new approach to carrier cooperation is presented: the sharing of warehouses or distribution centres with collaborating partners. By jointly and optimally deciding on two types of decisions, namely, first which distribution centres to open and second how to allocate the quantity of product flows to each open distribution centre, partnering companies aim to minimise their total logistics cost. Third, the cooperation challenges are tackled from an intermodal perspective. Bundling freight of multiple shippers offers the opportunity to achieve economies of scale, increase shipment frequencies and boost the competitiveness of intermodal barge transport.

Based on extensive statistical analyses using both artificial and real data, the following insights on partner selection and cost allocation are formulated. The most profitable horizontal coalitions consist of partners complementary in terms of company size, customer requests and geographical coverage. Furthermore, adding more partners to the collaboration does not necessarily mean more collaborative savings. Regarding the allocation of collaborative costs and profits, partners need to decide which properties are regarded the most important considering the characteristics of the cooperation project and its participants. Finally, results show the influence of cooperation structure on the longevity of cooperation projects, both in a unimodal and intermodal environment.

This PhD thesis was funded by the Research Foundation Flanders (FWO, grant number $11 \mathrm{C} 8815 \mathrm{~N})$. The authors declare that they have no conflict of interest. 